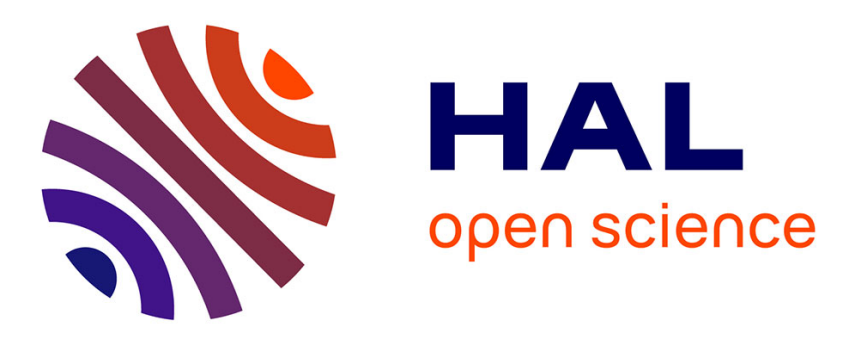

\title{
Follow-up of GK rats during prediabetes highlights increased insulin action and fat deposition despite low insulin secretion
}

\author{
Jamileh Movassat, Danièle Bailbe, Cecile Lubrano-Berthelier, Françoise \\ Picarel-Blanchot, Eric Bertin, Jacques Mourot, Bernard Portha
}

\section{To cite this version:}

Jamileh Movassat, Danièle Bailbe, Cecile Lubrano-Berthelier, Françoise Picarel-Blanchot, Eric Bertin, et al.. Follow-up of GK rats during prediabetes highlights increased insulin action and fat deposition despite low insulin secretion. AJP - Endocrinology and Metabolism, 2008, 294 (1), pp.E168-E175. 10.1152/ajpendo.00501.2007 . hal-02664725

\section{HAL Id: hal-02664725 \\ https://hal.inrae.fr/hal-02664725}

Submitted on 31 May 2020

HAL is a multi-disciplinary open access archive for the deposit and dissemination of scientific research documents, whether they are published or not. The documents may come from teaching and research institutions in France or abroad, or from public or private research centers.
L'archive ouverte pluridisciplinaire HAL, est destinée au dépôt et à la diffusion de documents scientifiques de niveau recherche, publiés ou non, émanant des établissements d'enseignement et de recherche français ou étrangers, des laboratoires publics ou privés. 


\section{Jamileh Movassat, Danièle Bailbé, Cécile Lubrano-Berthelier, Françoise}

Picarel-Blanchot, Eric Bertin, Jacques Mourot and Bernard Portha

Am J Physiol Endocrinol Metab 294:168-175, 2008. First published Nov 6, 2007;

doi:10.1152/ajpendo.00501.2007

You might find this additional information useful...

This article cites 44 articles, 22 of which you can access free at:

http://ajpendo.physiology.org/cgi/content/full/294/1/E168\#BIBL

This article has been cited by 2 other HighWire hosted articles:

IL-1 antagonism reduces hyperglycemia and tissue inflammation in the type 2 diabetic GK rat

J. A. Ehses, G. Lacraz, M.-H. Giroix, F. Schmidlin, J. Coulaud, N. Kassis, J.-C. Irminger, M.

Kergoat, B. Portha, F. Homo-Delarche and M. Y. Donath

PNAS, August 18, 2009; 106 (33): 13998-14003.

[Abstract] [Full Text] [PDF]

Mechanism-Based Modeling of Nutritional and Leptin Influences on Growth in Normal and Type 2 Diabetic Rats

C. B. Landersdorfer, D. C. DuBois, R. R. Almon and W. J. Jusko

J. Pharmacol. Exp. Ther., February 1, 2009; 328 (2): 644-651.

[Abstract] [Full Text] [PDF]

Updated information and services including high-resolution figures, can be found at:

http://ajpendo.physiology.org/cgi/content/full/294/1/E168

Additional material and information about AJP - Endocrinology and Metabolism can be found at: http://www.the-aps.org/publications/ajpendo

This information is current as of September 2, 2010 .

AJP - Endocrinology and Metabolism publishes results of original studies about endocrine and metabolic systems on any level of organization. It is published 12 times a year (monthly) by the American Physiological Society, 9650 Rockville Pike, Bethesda MD 20814-3991. Copyright @ 2008 by the American Physiological Society. ISSN: 0193-1849, ESSN: 1522-1555. Visit our website at http://www.the-aps.org/. 


\title{
Follow-up of GK rats during prediabetes highlights increased insulin action and fat deposition despite low insulin secretion
}

\author{
Jamileh Movassat, ${ }^{1}$ Danièle Bailbé, ${ }^{1}$ Cécile Lubrano-Berthelier, ${ }^{1}$ Françoise Picarel-Blanchot, ${ }^{1}$ Eric Bertin, ${ }^{1}$ \\ Jacques Mourot, ${ }^{2}$ and Bernard Portha ${ }^{1}$ \\ ${ }^{1}$ Unité Mixte de Recherche 7059, Centre National Pour la Recherche Scientifique and Université Paris, Diderot and ${ }^{2}$ Unité \\ Mixte de Recherche 1079, Institut National pour la Recherche Agronomic and Ecole Nationale Superieure d'Agronomie de \\ Rennes, St. Gilles, France
}

Submitted 1 August 2007; accepted in final form 31 October 2007

\begin{abstract}
Movassat J, Bailbé D, Lubrano-Berthelier C, Picarel-Blanchot F, Bertin E, Mourot J, Portha B. Follow-up of GK rats during prediabetes highlights increased insulin action and fat deposition despite low insulin secretion. Am J Physiol Endocrinol Metab 294: E168-E175, 2008. First published November 6, 2007; doi:10.1152/ajpendo.00501.2007.-The adult Goto-Kakizaki (GK) rat is characterized by impaired glucoseinduced insulin secretion in vivo and in vitro, decreased $\beta$-cell mass, decreased insulin sensitivity in the liver, and moderate insulin resistance in muscles and adipose tissue. GK rats do not exhibit basal hyperglycemia during the first $3 \mathrm{wk}$ after birth and therefore could be considered prediabetic during this period. Our aim was to identify the initial pathophysiological changes occurring during the prediabetes period in this model of type 2 diabetes (T2DM). To address this, we investigated $\beta$-cell function, insulin sensitivity, and body composition in normoglycemic prediabetic GK rats. Our results revealed that the in vivo secretory response of GK $\beta$-cells to glucose is markedly reduced and the whole body insulin sensitivity is increased in the prediabetic GK rats in vivo. Moreover, the body composition of suckling GK rats is altered compared with age-matched Wistar rats, with an increase of the number of adipocytes before weaning despite a decreased body weight and lean mass in the GK rats. None of these changes appeared to be due to the postnatal nutritional environment of GK pups as demonstrated by cross-fostering GK pups with nondiabetic Wistar dams. In conclusion, in the GK model of T2DM, $\beta$-cell dysfunction associated with increased insulin sensitivity and the alteration of body composition are proximal events that might contribute to the establishment of overt diabetes in adult GK rats.
\end{abstract}

Goto-Kakizaki rat; body composition; insulin sensitivity; glucose tolerance

ESTABLISHED TYPE 2 DIABETES MELLITUS (T2DM) is associated with profound insulin-secretory alterations and insulin resistance, but the primacy of each of these events over the other remains controversial. According to a widely accepted hypothesis, insulin resistance is the primary defect responsible for the progression toward T2DM $(8,30,34,48)$. However, other data support the concept that $\beta$-cell dysfunction could be, in fact, a proximal event rather than a secondary phenomenon due to the exhaustion of $\beta$-cells caused by prolonged insulin resistance (16). This controversy may partly result from the genetic heterogeneity of the population included in the study protocols in humans with high risk of developing the disease, and the presence of confounding parameters such as age, sex, and environmental factors (16). Therefore, animal models of T2DM with a period of prediabetes could help with the

Address for reprint requests and other correspondence: J. Movassat, CNRS UMR 7059, Université Paris 7/D. Diderot, 2, Place Jussieu, F-75251 Paris, France (e-mail: movassat@paris7.jussieu.fr). understanding of the chronology of events leading to the appearance of clinical symptoms. The Goto-Kakizaki (GK) rat is a spontaneous nonoverweight model of T2DM produced by selective breeding (with glucose intolerance as selection criterion) repeated over many generations, starting from a nondiabetic Wistar colony. In the colony maintained in our laboratory (GK/Par line) with progenitors issued from the original Japanese colony (18), all adult animals exhibit mild hyperglycemia and impaired glucose tolerance. In vivo and in vitro studies indicate that insulin release in response to glucose is markedly affected in adult GK/Par rats $(39,40)$. $\beta$-Cell number is also depleted by $50 \%$ (32), and insulin sensitivity is reduced in the liver, muscle, and adipose tissue of adult GK/Par rats $(7,37)$. Because in GK/Par rats hyperglycemia does not appear before weaning $(7,37)$, during the first 3 wk after birth the GK/Par rats can be considered prediabetic and therefore represent a valuable model for studying the initial pathophysiological changes relevant to the alteration of glucose metabolism in adult GK rats. In the present work, we focused on the identification of the primary determinants in the pathogenesis of diabetes in this model of T2DM.

\section{MATERIALS AND METHODS}

Animals. Diabetic GK/Par rats were obtained from our laboratory (39). Nondiabetic Wistar rats were used as controls. For all experiments, newborn litters were limited to $8-10$ pups by removal of additional pups on the day of birth, since the size of the litter has short- and long-term influences on body weight, adipose tissue cellularity, and insulin production $(25,28)$. Females $7,14,21,28$, and 56 days old were used for this study. Animals were weaned on day 28 and fed ad libitum with commercial chows (Diet 113; SAVE, France). All animal experiments were conducted with the approval of the French National Centre for Scientific Research.

Cross-fostering experiments. Immediately after birth, offspring of GK and Wistar rats were cross-fostered respectively to Wistar and GK dams having given birth the same day.

The maternal behavior of the GK and Wistar dams fostering Wistar and GK pups, respectively, was examined daily to ensure that there was no maternal rejection.

Glucose tolerance test. Intraperitoneal glucose tolerance tests (IPGTT) were performed in nonanesthetized animals. Newborn rats were separated from their mothers $2 \mathrm{~h}$ before the experiments. Animals from at least three different litters were used at the ages of 7 , 14, and 21 days in Wistar and GK groups and at the ages of 14 and 21 days in the cross-fostered GK (CFGK) group. Blood samples were collected before and 10, 30, and 60 min after glucose administration

The costs of publication of this article were defrayed in part by the payment of page charges. The article must therefore be hereby marked "advertisement" in accordance with 18 U.S.C. Section 1734 solely to indicate this fact. 
(1 $\mathrm{g} / \mathrm{kg}$ body wt) for determination of plasma glucose and insulin. Because of the small size of the animals at these ages, 6-9 animals were killed by decapitation for each time point of the IPGTT in order to collect sufficient volume of plasma for the determination of plasma insulin, making a total of 24-36 animals in each experimental group. For 28- and 56-day-old rats, eight animals from each group were used, and blood samples were collected from the tail vein.

Carcass composition. After a homogenous mixture of the carcass had been obtained using a mechanical grinder, the water content of the carcass was determined by weight loss after drying $1 \mathrm{~g}$ of samples for $18 \mathrm{~h}$ in a $103^{\circ} \mathrm{C}$ oven. Total lipid content was determined on three aliquots after extraction with a mixture of chloroform-methanol (2:1) as previously described $(1,6,44)$. Nitrogen was determined by semimicro-Kjeldahl digestion and converted to protein mass with the correction factor 6.25 (44).

Glucose turnover rate in basal state. Glucose turnover rate was measured according to a previously detailed procedure (24) in anesthetized (pentobarbital sodium $50 \mathrm{mg} / \mathrm{kg}$ ip) 21-day-old pups separated from their mothers $3 \mathrm{~h}$ before the experiments. In these conditions, rats were considered to be in the postabsorptive period, and the rate of glucose production was a measure of endogenous production.

Glucose turnover in hyperinsulinemic-euglycemic clamp. Clamp studies were performed using a protocol previously validated in our laboratory (24) in 21-day-old Wistar and GK rats separated from their mothers $3 \mathrm{~h}$ before the experiments. Rats were anesthetized with pentobarbital sodium $(50 \mathrm{mg} / \mathrm{kg}$ body wt ip). Body temperature was maintained at $37^{\circ} \mathrm{C}$ with heating lamps. Blood was collected at the tail vein $15 \mathrm{~min}$ after anesthesia for the determination of basal blood glucose and plasma insulin concentrations. The rats were then administered a continuous intraperitoneal infusion of insulin $(100 \mathrm{UI} / \mathrm{ml}$ Actrapid, Novo Nordisk) at constant rate of $20 \mu \mathrm{l} / \mathrm{min}(17 \mathrm{mU} / \mathrm{min})$. Blood glucose was clamped at $6 \mathrm{mmol} / \mathrm{l}$ by a variable intraperitoneal infusion of glucose with a Precidor pump (Infors, Basel, Switzerland). This level of blood glucose corresponds to basal glycemia in 21-dayold Wistar rats and to basal glucose levels in nonanesthetized 21-dayold GK rats. After the beginning of insulin infusion, blood samples were collected from the tail vein every $5 \mathrm{~min}$, and blood glucose concentrations were measured using a glucometer (Glucotrend, Boehringer Mannheim). In each group, the steady-state plasma insulin and blood glucose levels were reached 70-75 min after the beginning of insulin infusion. Endogenous glucose production during the clamp studies was assessed by a primed continuous infusion of $\left[3-{ }^{3} \mathrm{H}\right] \mathrm{glu}-$ cose (Amersham). The labeled glucose was administrated as an initial intraperitoneal priming dose $(5 \mu \mathrm{Ci})$ followed immediately by a continuous intraperitoneal infusion at a rate of $0.2 \mu \mathrm{Ci} / \mathrm{min}$. A steady state of glucose-specific activity was established by $70 \mathrm{~min}$ in the clamp studies.

Insulin sensitivity test. Intraperitoneal insulin sensitivity tests were performed in nonanesthetized 7-, 14-, and 21-day-old GK and Wistar rats after 3-h separation from their mothers. Human insulin (Actrapid) was injected at the dose of $0.375 \mathrm{U} / \mathrm{kg}$ body wt, and blood samples were collected from the tail before and 5, 10, 15, 20, 40, 60, and 90 min later for the determination of blood glucose concentrations.

Samples, analytic techniques, and calculations. Retroperitoneal adipose tissues were dissected and weighed. The average volume and number of adipocytes per fat pad were determined according to the technique of Sjoström et al. (44), as previously detailed (19). Fat mass and protein mass were calculated and expressed as grams per 100 grams fresh weight. As previously described (24), plasma immunoreactive insulin was estimated using purified rat insulin as standard (Cliniscience, Montrouge, France), antibody to insulin and rat ${ }^{125} \mathrm{I}-$ labeled monoiodated insulin (Diasorin, Saluggia, Italy) as tracer. Charcoal (Sigma, L'Isle d'Abeau Chesnes, France) was used to separate free from bound hormone. This method allows the determination of $0.1 \mathrm{ng} / \mathrm{ml}$ with a coefficient of variation within and among assays of $10 \%$. Insulin and glucose responses during the IPGTT were calculated as the incremental values of plasma insulin $(\Delta \mathrm{I})$ and plasma glucose $(\Delta \mathrm{G})$ above basal values (T0) of insulin and glucose, respectively, integrated over the period $(60 \mathrm{~min})$ following the injection of glucose.

Glucose specific activity in the blood samples was measured as detailed in Ref. 12. Glucose turnover was calculated by dividing the $\left[3-{ }^{3} \mathrm{H}\right]$ glucose infusion rate (GIR) by the glucose specific activity under steady-state conditions. In the basal state, endogenous glucose production was considered equal to the rate of glucose appearance, and it equaled the glucose utilization rate. The insulin sensitivity index (ISI) was calculated by dividing the GIR required to maintain steadystate blood glucose by the steady-state plasma insulin concentration. Plasma glucose disappearance rate $\left(\mathrm{R}_{\mathrm{d}}\right.$ ins $\left.\% / \mathrm{min}\right)$ during the insulin sensitivity test was calculated from the slope of the regression line obtained with the log-transformed plasma glucose values from 5 to 40 min after insulin administration.

Statistical analysis. Results are expressed as means \pm SE. Statistical analyses were performed with analysis of variance and using Student's unpaired $t$-test.

\section{RESULTS}

Postnatal stunting with early alteration of body composition and adiposity in GK prediabetic rats. At birth, pups of GK dams exhibited normal body weight (data not shown), consistent with our previous reports (43).

However, from day 2 after birth and onward, they did have a mean weight-for-age deficit compared with the age-matched Wistar rats, with no catch-up growth after weaning or with aging (Fig. 1) (4). In the GK pups reared with Wistar dams, there was no supplementary weight gain compared with GK pups reared with their own mothers (Fig. 1). This occurred in the absence of rejection of Wistar dams toward GK pups, since the nursing behavior checked daily during the length of the experiment appeared normal. At 7 and 14 days of age, the GK offspring had similar percent protein mass but a lower percentage of body fat mass and retroperitoneal fat pad to body weight (at 14 days) than controls (Table 1). At weaning (28 days) and thereafter, the lean body mass and the percentages of protein mass lowered. This was accompanied by a significant increase in percent body fat mass and absolute retroperitoneal fat pad weight. These data reveal an unexpected accumulation of total body lipids in the GK rat at the time of the weaning transition, with mainly an excess of fat in the retroperitoneal depots.

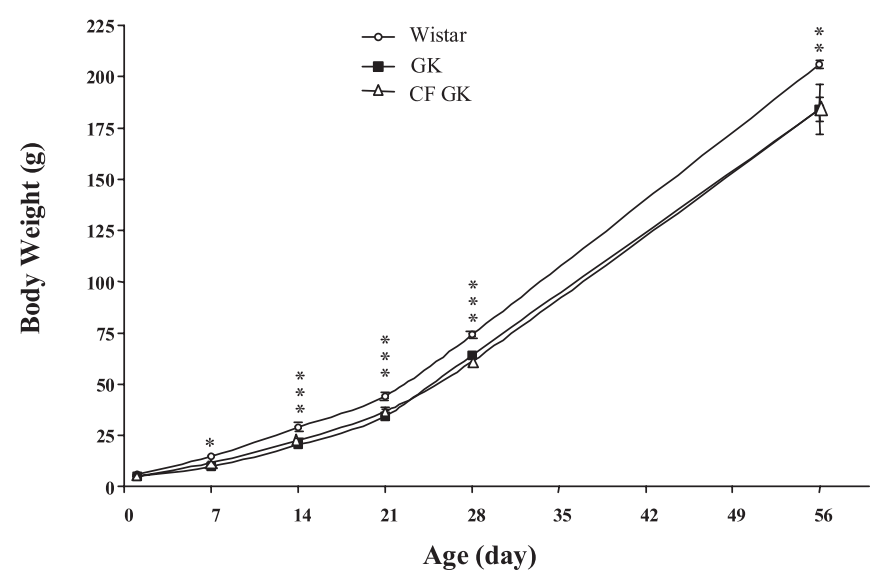

Fig. 1. Postnatal growth in Wistar, GK, and cross-fostered GK (CFGK) rats from day 1 to day 56 of life. Results are expressed as means \pm SE. $* P<0.05$, $* * P<0.01, * * * P<0.001$ Wistar vs. age-matched GK and CFGK groups. Wistar, $n=16$; GK, $n=15$; CFGK, $n=10$. 
Table 1. Age-dependent changes in body composition and adiposity in GK and control Wistar rats

\begin{tabular}{|c|c|c|c|c|c|c|c|c|c|c|}
\hline Rats & $n$ & Age, days & \multicolumn{4}{|c|}{ Body Composition } & \multicolumn{4}{|c|}{ RP Fat } \\
\hline & 5 & 7 & $15.9 \pm 0.3$ & $14.8 \pm 0.2$ & $12.9 \pm 0.08$ & $6.9 \pm 0.3$ & ND & ND & ND & ND \\
\hline & 5 & 14 & $24.8 \pm 0.1$ & $22.3 \pm 0.2$ & $14.7 \pm 0.24$ & $10.1 \pm 0.6$ & $83 \pm 9$ & $0.24 \pm 0.02$ & $127 \pm 16$ & $7.5 \pm 0.1$ \\
\hline & 5 & 28 & $101.0 \pm 3.1$ & $92.6 \pm 2.3$ & $16.9 \pm 0.19$ & $8.6 \pm 0.5$ & $252 \pm 31$ & $0.29 \pm 0.03$ & $201 \pm 20$ & $6.5 \pm 0.9$ \\
\hline & 7 & 56 & $192.1 \pm 4.0$ & $167.2 \pm 5.1$ & $19.5 \pm 0.31$ & $12.9 \pm 1.3$ & $1,100 \pm 92$ & $0.56 \pm 0.07$ & $226 \pm 29$ & $22.5 \pm 2.4$ \\
\hline \multicolumn{11}{|l|}{ GK } \\
\hline & 5 & 14 & $19.8 \pm 0.4$ & $18.6 \pm 0.3^{\mathrm{c}}$ & $14.7 \pm 0.07$ & $6.7 \pm 0.2^{\mathrm{b}}$ & $20 \pm 2^{b}$ & $0.10 \pm 0.01^{\mathrm{c}}$ & $21 \pm 2^{c}$ & $10.8 \pm 1.0^{\mathrm{c}}$ \\
\hline & 8 & 28 & $64.1 \pm 1.7$ & $56.8 \pm 1.4^{\mathrm{c}}$ & $16.0 \pm 0.15$ & $11.1 \pm 0.3^{\mathrm{b}}$ & $380 \pm 30^{\mathrm{a}}$ & $0.37 \pm 0.02^{\mathrm{a}}$ & $154 \pm 6^{\mathrm{a}}$ & $13.3 \pm 1.4^{\mathrm{b}}$ \\
\hline & 7 & 56 & $119.3 \pm 15.0$ & $111.2 \pm 2.4^{\mathrm{b}}$ & $18.2 \pm 0.19$ & $16.5 \pm 0.4^{\mathrm{a}}$ & $1,430 \pm 102^{\mathrm{a}}$ & $0.77 \pm 0.07^{\mathrm{a}}$ & $421 \pm 60^{\mathrm{a}}$ & $16.0 \pm 1.5^{\mathrm{a}}$ \\
\hline
\end{tabular}

Values are means \pm SE. W, Wistar; GK, Goto-Kakizaki; RP, retroperitoneal; ND, not determined. ${ }^{\text {a } P<0.05, ~}{ }^{\mathrm{b}} P<0.01,{ }^{\mathrm{c}} P<0.001$ vs. age-matched Wistar group.

The relative changes in fat cell number and size for GK and Wistar retroperitoneal depots were also determined as a function of age (Table 1). In both the 14- and the 28-day-old GK pups, the adipocyte number was significantly higher compared with age-matched Wistar rats, but at the age of 56 days it became significantly lower.

The mean cell volume was decreased in the 14- and 28-dayold GK pups compared with age-matched controls, whereas it became significantly higher in the 56-day-old GK pups (Table 1). Therefore, before weaning, fat cell number is higher but cells are smaller in GK pups. The impressive lipid accumulation in the GK retroperitoneal pads at the time of the weaning transition is illustrated by a sevenfold increase in adipocyte volume and a 1.2-fold increase in adipocyte number in the GK rats between 14 and 28 days, whereas the corresponding parameters are only modestly increased in the Wistar rats during the same period. Subsequently (from weaning to adulthood), fat cell number continued to increase in the GK rats, while fat cell enlargement became more prominent in the GK than in Wistar rats. In 56-day-old GK rats, fat cell enlargement rather than cell number represented the overwhelming feature of the fat mass overgrowth in the GK rat.

Basal plasma glucose and glucose tolerance are kept normal in GK pups despite severely defective insulin response. Basal plasma glucose levels in nonanesthetized 7-, 14-, and 21-day- old GK rats were similar to those of the Wistar rats of comparable ages. In line with our previous observation (31), from 28 days onward, basal glycemia significantly increased in GK rats and remained elevated thereafter (Table 2). After intraperitoneal glucose administration, the plasma glucose levels rose in an almost similar manner in both groups and the integrated glucose responses $(\Delta \mathrm{G})$ were not significantly higher in the GK than in the Wistar pups of matched ages, as shown in Fig. 2 and Table 2, except in 14-day-old rats, in which a slight glucose intolerance was apparent. From 7 days of age, the GK offspring had decreased basal plasma insulin and insulin-to-glucose ratio (Table 2). As assessed by IPGTT (Table 2 and Fig. 2), from 7 days onward, Wistar rats underwent a high increase in plasma insulin levels in response to glucose. By contrast, GK rats exhibited a blunted response so that the integrated insulin response $(\Delta \mathrm{I})$ was markedly decreased on day 7, day 14, and day 21 (Table 2). In Wistar rats, $\Delta \mathrm{I}$ was significantly increased between day 21 and day 28 , the time of weaning. It can be pointed out that, in the 28-day-old GK rats, $\Delta \mathrm{I}$ was also strongly increased compared with that of the 21-day-old GK rats (Table 2). However, despite the improvement of the GK insulin response detected at that age, this parameter remained significantly reduced at 28 and 56 days of age compared with the age-matched Wistar (Table 2).

Table 2. Age-dependent changes in basal plasma glucose and insulin levels, glucose tolerance, and insulin-secretory response in GK and control Wistar rats

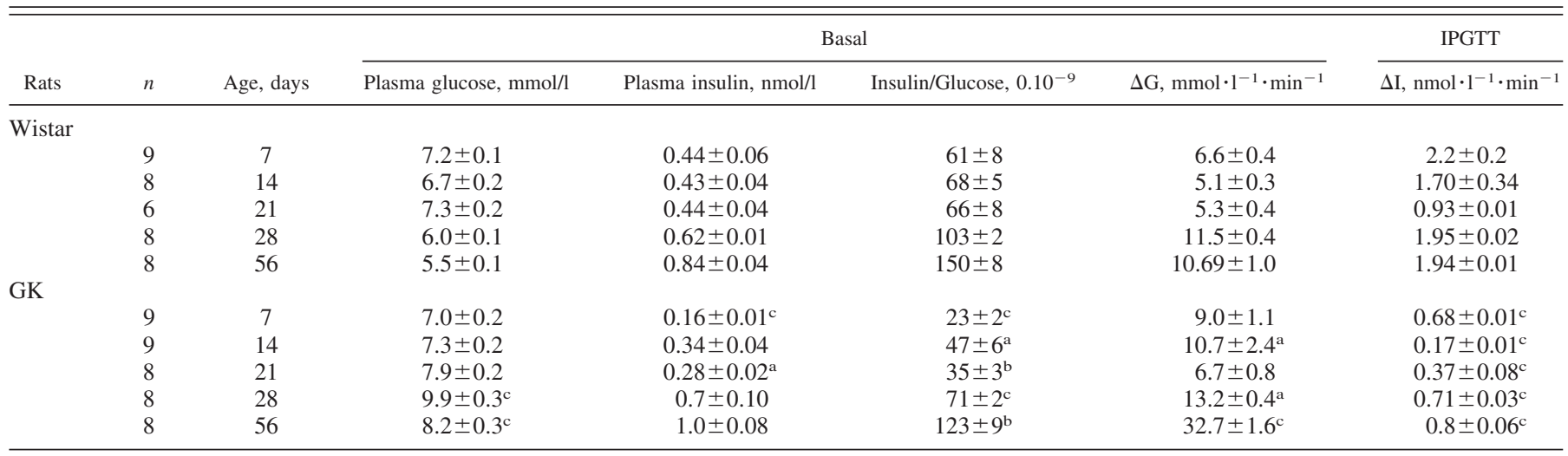

Values are means \pm SE. IPGTT, ip glucose tolerance test; $\Delta \mathrm{G}$, mean incremental values of plasma glucose above basal values of glucose (T0), integrated over the period of the IPGTT test $(60 \mathrm{~min}) ; \Delta \mathrm{I}$, mean incremental values of plasma insulin above basal values of insulin (T0), integrated over the period of the IPGTT test $(60 \mathrm{~min}) .{ }^{\mathrm{a}} P<0.05,{ }^{\mathrm{b}} P<0.01,{ }^{\mathrm{c}} P<0.001$ vs. age-matched Wistar group. 

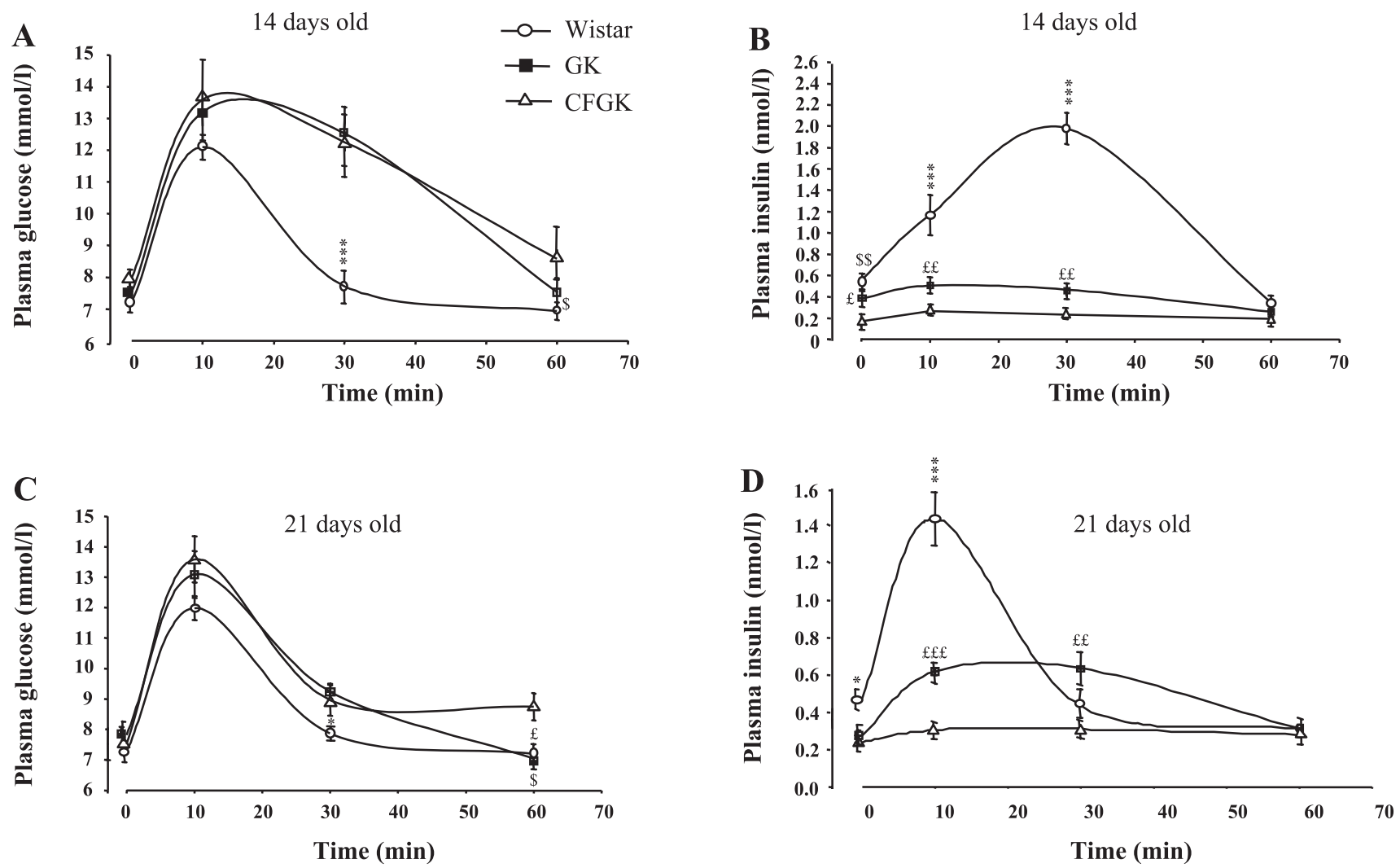

Fig. 2. Intraperitoneal glucose tolerance test in 14- and 21-day-old Wistar, GK, and CFGK rats. Time courses of plasma glucose concentrations $(A$ and $C)$ and plasma insulin concentrations $(B$ and $D$ ) are shown. Results are expressed as means $\pm \mathrm{SE}$. $* P<0.05, * * P<0.01$, $* * * P<0.001$, Wistar vs. age-matched GK and CFGK groups; $\$ P<0.05$ and $\$ \$ P<0.01$, Wistar vs. age-matched CFGK group; $£ P<0.05$ and $£ £ P<0.01$, GK vs. age-matched CFGK group. 14-day-old rats: Wistar, $n=8$; GK, $n=7$; CFGK, $n=7$; 21-day-old rats: Wistar, $n=6$; GK, $n=6$; CFGK, $n=7$.

IPGTT performed in 14- and 21-day-old GK pups reared with Wistar dams revealed no significant differences in the basal glucose levels and in the evolution of plasma glucose during the test between this group and that of GK pups reared with GK dams (Fig. 2). However, basal plasma insulin and plasma insulin levels during the test were decreased in CFGK rats compared with GK and Wistar groups.

Overall glucose utilization rate was increased in GK prediabetic rats in both the basal and the hyperinsulinemic states. Blood (or plasma) glucose and plasma insulin concentrations in the basal state and during hyperinsulinemic clamp (anesthetized animals) are shown in Table 3.

Basal glucose utilization rates are expressed on a per kilogram of body weight basis, to take into account the differences in body mass between the two lines of rats, which are significantly greater $(P<0.01)$ in the 21 -day-old Wistar rats than in the GK rats. The metabolic clearance rate of glucose was not decreased in GK compared with controls (Table 3). It is then likely that the higher glucose utilization rate in the 21-day-old GK rats resulted essentially from the $23 \%$ increase in their steady-state blood glucose (Table 3).

Since during hyperinsulinemic and euglycemic conditions endogenous glucose production in both groups was completely abolished (data not shown), the GIR was evaluated by the calculation of exogenous GIR required to maintain euglycemia. This parameter was found significantly higher in the 21-day-old GK rats compared with Wistar rats. The ISI in the GK group was 95\% higher than in control group.

To assess comparative changes in insulin action in younger rats and to avoid general anesthesia, we measured the acute effect of a single intraperitoneal injection of insulin on blood glucose as a function of age in 7-, 14-, and 21-day-old Wistar,

Table 3. Age-dependent changes in glucose kinetics and overall insulin action in 21-day-old GK and control Wistar rats

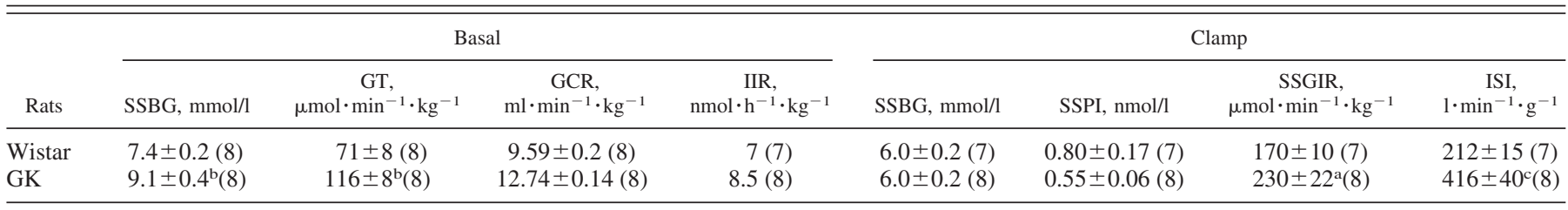

Values are means \pm SE; no. of rats in parentheses. IIR, insulin infusion rate; SSPI, steady-state plasma insulin; SSGIR, steady-state glucose infusion rate; GT, glucose turnover; GCR, glucose clearance rate: ratio of glucose turnover rate (GT) to steady-state blood glucose (SSBG). Rats were sampled in the basal state or during euglycemic hyperinsulinemic clamp. ISI was calculated by dividing GIR required to maintain euglycemia by SSPI. ${ }^{\mathrm{a}} P<0.05$, ${ }^{\mathrm{b}} P<0.01,{ }^{\mathrm{c}} P<0.001$ vs. age-related Wistar group. 
' $\mathrm{GK}$, and CFGK rats. The $\mathrm{R}_{\mathrm{d} \text { ins }}$ was significantly greater in the 7-, 14-, and 21-day-old GK rats compared with the agematched Wistar rats (Fig. 3), thus indicating an increased sensitivity to insulin. Interestingly, the whole body insulin sensitivity of the CFGK rats was similar (days 7 and 21 ) or higher (day 14) than that of GK rats reared with GK dams and higher than insulin sensitivity of age-matched Wistar pups (Fig. 3).

\section{DISCUSSION}

The occurrence of basal hyperglycemia and diabetes in the GK/Par rat is preceded by a period of prediabetes during which animals are normoglycemic.

Here, we show that abnormal $\beta$-cell function is a primary defect in the time course of the events leading to diabetes in adult individual. Indeed, in normoglycemic GK neonates, the basal plasma insulin levels and the insulin-to-glucose ratio are dramatically reduced, and during this prediabetes period, the glucose-induced insulin secretion in vivo is markedly decreased as measured during glucose tolerance tests. Such a $\beta$-cell dysfunction has been implicated in the pathogenesis of diabetes associated with low birth weight in mice (22). Importantly, studies in humans also report that $\beta$-cell dysfunction could be a proximal defect in the process of developing glucose intolerance and diabetes $(12,14,23,47)$.

In our model, $\beta$-cell dysfunction occurred in the absence of glucose intolerance in prediabetic GK rats, whereas after weaning GK rats become clearly glucose intolerant. The basal normoglycemia and the normal glucose tolerance in GK neonates could be explained if the impaired insulin secretion was compensated for by an increased sensitivity to insulin. To verify this, we assessed insulin sensitivity with two independent methods. We performed insulin sensitivity tests in 7-, 14-, and 21-day-old animals, which showed that insulin action was significantly increased in GK rats compared with the agematched Wistar rats.
We also assessed the overall glucose utilization in the basal and hyperinsulinemic states in 21-day-old GK rats. When measured in the basal state, the glucose utilization rate obtained through glucose turnover measurement was found greater in prediabetic GK rats than in controls. Because this was obtained in the presence of a low basal plasma insulin level but normal basal plasma glucose, it again suggests that the peripheral tissues are hyperreactive to insulin action in these rats. During hyperinsulinemic and euglycemic conditions, endogenous glucose production in both groups being completely abolished, the GIR was evaluated by the exogenous GIR required to maintain euglycemia. It was found significantly higher in the 21-day-old GK rats compared with Wistar rats. This whole set of data indicates that before weaning GK rats exhibit a significant insulin hypersensitivity, which is reversed after that time, aqs adult GK rats exhibit insulin resistance (7). Strikingly, this pattern in the young prediabetic GK rat is reminiscent of the situation in the 4-wk-old normoglycemic n0-STZ (streptozotocin) rats (24). In this model also, the basal plasma insulin and the glucose-induced insulin secretion are significantly reduced, but the whole body insulin-mediated glucose uptake as well as the insulin-dependent glucose utilization by white and brown adipose tissues are clearly increased (24). The underlying mechanisms of insulin hypersensitivity in the GK rat before the onset of diabetes are not known. They perhaps reflect an adaptation to the very low circulating insulin levels. However, this adaptative mechanism cannot overcome the lack of appropriate insulin secretion when rats are fed a high-carbohydrate diet after weaning, resulting in progressive glucose intolerance and diabetes in adult GK rats. The neonatal GK rats could bear some resemblance to other pathological situations in rodents associated with increased insulin sensitivity, decreased $\beta$-cell mass, and decreased basal glucose concentrations and insulin secretion, such as perinatal undernutrition in the rat (10) or GH receptor deficiency in transgenic mice $(9,29)$.
Fig. 3. Intraperitoneal insulin sensitivity test in 7-, 14-, and 21-day-old Wistar $(n=10)$, GK $(n=13)$, and CFGK $(n=10)$ groups. Glucose disappearance rate $\left(\mathrm{R}_{\mathrm{d} \text { ins }}, \% / \mathrm{min}\right)$ in response to insulin injection was calculated from the slope of the regression line on the basis of the logarithm of plasma glucose values obtained during the 5- to 40-min period of the insulin tests. Results are expressed as means \pm SE. $* P<$ $0.05, * * P<0.01, * * * P<0.001 ;$ ns, not significant.

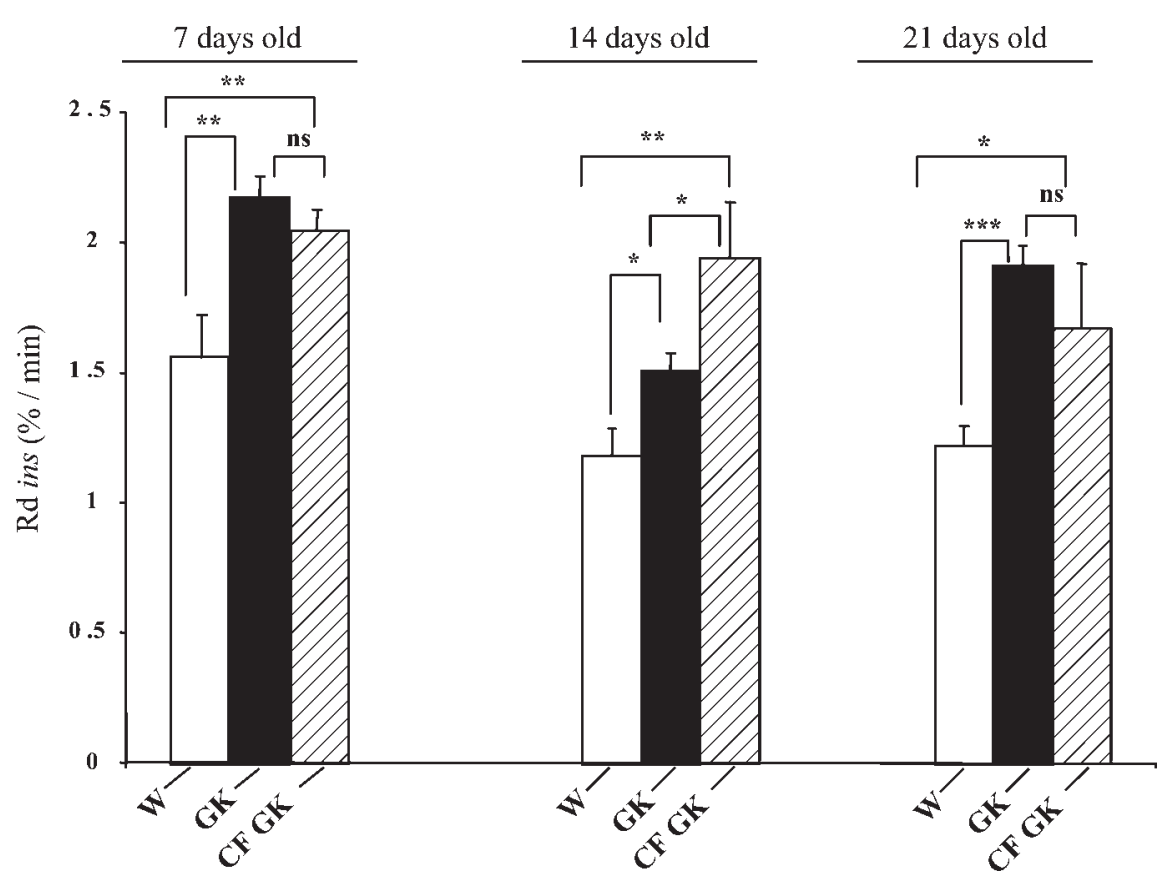

AJP-Endocrinol Metab $・$ VOL $294 \cdot$ JANUARY $2008 \cdot$ www.ajpendo.org 
In the GK model, the possibility remained, however, for those changes in the metabolic parameters to be caused by qualitative and/or quantitative changes in the maternal milk and the nursing behavior of diabetic GK dams. This has been described in offspring of STZ-diabetic dams (11). In that model, the authors reported a marked decrease in milk synthesis and ejection, leading potentially to quantitative undernutrition in the offspring (26). Moreover, it has been reported that NZO mouse pups (a genetic model for obesity and T2DM) suckled by diabetic mothers became more obese in adulthood compared with those reared by control dams, independent of their genetic background (41). In humans also, ingestion of breast milk from diabetic mothers may dose-dependently increase the risk of obesity in early childhood (38). To test whether such is also the case in the GK model, we performed cross-fostering experiments from the day of birth and until weaning. Interestingly, our results indicate that GK pups reared with nondiabetic Wistar dams having normal milk composition and normal maternal behavior exhibit similar defects in glucose secretion during the IPGTT and a comparable increase in the whole body insulin sensitivity to those of GK pups reared with their own diabetic GK mothers. This suggests that in this specific model of T2DM alteration of metabolic parameters during the prediabetes stage is due preeminently to genetic predisposition and that normal postnatal nutrition and nursing behavior cannot significantly affect the occurrence of such abnormalities. Interestingly, in an embryo transfer experiment, Gill-Randall et al. (17) showed that the transfer of a fertilized GK egg into a Wistar uterus did not overcome the genetic predisposition of the offspring to develop glucose intolerance and impaired fasting glucose, again suggesting the predominance of genetic background in the GK model. Conversely, they showed that the transfer of a genetically low-risk Wistar embryo into GK uterus increased the risk of developing glucose intolerance (17). In line with this observation, we found that Wistar pups reared with diabetic GK dams exhibit growth retardation and alteration of glucoseinduced insulin secretion in vivo (data not shown), suggesting that individuals with genetically low risk could increase their risk of developing metabolic alterations when exposed to a modified nutritional environment. Data on the state of insulin sensitivity in the prediabetes stage are variable, ranging from decreased insulin sensitivity $(13,33)$ to normal or increased insulin sensitivity $(5,15,21)$. Increased insulin sensitivity has been reported during the first postnatal days in infants born small for gestational age compared with newborns having appropriate weight for gestational age (3). However, decreased insulin sensitivity was also reported in other studies, but this was mostly related to catch-up growth occurring after birth (45).

The GK rat is a nonoverweight model of T2DM. Although T2DM in humans is often associated with obesity, all diabetic patients are not obese, and in some populations the prevalence of diabetes increases despite low prevalence of obesity (23). In this study, we explored the postnatal growth, body composition, and adiposity in prediabetic and adult diabetic GK rats. We showed that prediabetic GK rats exhibited a progressive delay in postnatal growth. This decrease in weight gain is attributed to a decreased growth in length. This is reflected by the diminution of both their lean mass and fat mass-to-body mass ratio, at least during the period of 7-14 days. At the time of weaning (28 days) and thereafter (56 days), although the lean body mass deficit persisted in the GK rats, their body fat accumulation was unexpectedly turned on. The clear-cut increase in percent body fat mass and retroperitoneal adipose tissue weight in the GK rats (28- and 56-day-old) compared with nondiabetic rats was a salient finding. As a consequence, the statement that the GK rat is a model for T2DM without obesity $(35,40)$ has to be revisited: despite its low body weight, the GK rat exhibits excessive fat accumulation (in proportion to body weight) especially at the onset of hyperglycemia. This pattern is again very close to that reported in the neonatal-STZ model of early hypoinsulinism (24). Moreover, fat cell volume and number were respectively increased and decreased in both models at 58 days compared with agematched controls (19).

The alteration in body composition of GK rats with excessive fat cell number (prediabetic GK rat) and fat cell size (hyperglycemic GK rat) would most likely implicate changes in the synthesis and secretion of adipocyte-derived hormones in this model. Preliminary results in our GK/Par colony show that the levels of plasma leptin are lower in prediabetic GK rats than those in age-matched Wistar rats, whereas in hyperglycemic GK rats circulating leptin is at a higher level than that found in adult Wistar rats (J. Ehses, M. Donath, F. HomoDelarche, personal communication). Changes in the levels of other adipokines need to be further investigated in the GK rats.

To summarize, these data reveal a major, and so far unsuspected, difference in the prediabetic GK fat cell ontogenesis compared with nondiabetic Wistar: fat accretion in the GK rat after weaning would be due at first to a more precocious (14 days) hyperplasia of hypotrophic adipocytes, whereas later on (at and after weaning) increased cellularity is no longer maintained and hypertrophy becomes prominent. Finally, the changes in body composition in the prediabetic GK model are relevant to those described in adults and children of several populations (e.g., India and Brazil) $(2,27,42,46)$ in which there is evidence of low birth weight being associated with a tendency toward increased abdominal fat.

The suckling-weaning transition seems to be a very important step for overaccumulation of fat mass in the GK model, and it coincides with the appearance of basal hyperglycemia. The suckling-weaning transition in normal rats is characterized by increased insulin sensitivity and insulin secretion, which underlie the marked increase in size and lipid content that occurs in white adipose tissue at weaning. In susceptible rodents, this nutritional transition has been implicated in the development of overt obesity $(20,36)$. By analogy, we suggest that the development of the increased fat mass in the 56-dayold diabetic GK rat could be a consequence of increased glucose utilization by adipose tissue in the basal state before weaning. Therefore, from our previous (37) and present data it can be inferred that increased body fat mass may indeed result from a primary insulin deficiency and not only from excessive insulin levels, as is more generally recognized. The growthretarded phenotype of the young GK rat is strikingly similar to the $\mathrm{GHR}^{-1-}$ mice exhibiting growth retardation, hypoinsulinemia, oversensitivity to insulin, and enlargement of some fat pads (9). The possibility that deficient GH/IGF-I signaling could contribute to the fat phenotype development in the young GK rats needs to be documented in further studies. 
In summary, our results demonstrate the primacy of abnormal $\beta$-cell function in vivo very early in life in GK rats, which is compensated for by increased insulin sensitivity during the prediabetes period. The changes in the metabolic parameters in prediabetic GK rats are mostly imputable to genetic determinants and/or fetal programming rather than the early postnatal nutritional environment in this model of T2DM. Importantly, we show for the first time that the prediabetic GK pups are lighter and thinner but that their relative adipose mass is increased at weaning. Increase in relative adiposity is favored by increased glucose clearance and enhanced peripheral insulin action. Together with the excessive hepatic glucose production already reported (37), these unsuspected abnormalities in the GK/Par line might contribute to the development of overt diabetes. Further studies need to be undertaken regarding the cellular mechanisms underlying the deficient $\beta$-cell function and increased insulin sensitivity in suckling GK rats.

\section{ACKNOWLEDGMENTS}

We thank Monique Faro and Michela Miani for technical assistance.

\section{GRANTS}

This work was supported in part by the French Agence Naionale pour la Recherche Grant ANR-060-Physio-028-61.

\section{REFERENCES}

1. Abraham J, Morin-Jomain M, Peretianu J. Nouvelle technique de determination de la composition corporelle des animaux de laboratoire. Bull Soc Chim Biol 46: 755-758, 1964.

2. Barker M, Robinson S, Osmond C, Barker DJ. Birth weight and body fat distribution in adolescent girls. Arch Dis Child 77: 381-383, 1997.

3. Bazaes RA, Salazar TE, Pittaluga E, Peña V, Alegría A, Íñiguez G, Ong KK, Dunger DB, Mericq V. Glucose and lipid metabolism in small for gestational age infants at 48 hours of age. Pediatrics 111: 804-809, 2003.

4. Berthelier C, Kergoat M, Portha B. Lack of deterioration of insulin action with ageing in the GK rat. A contrasted pattern as compared to non-diabetic rat. Metabolism 46: 890-896, 1997.

5. Bertin E, Gangnerau MN, Bailbe D, Portha B. Glucose metabolism and $\beta$-cell mass in adult offspring of rats protein and/or energy restricted during the last week of pregnancy. Am J Physiol Endocrinol Metab 277: E11-E17, 1999.

6. Bertin E, Ruiz JC, Mourot J, Peiniau P, Portha B. Evaluation of dual-energy X-ray absorptiometry for body composition assessment in rats. J Nutr 128: 1550-1554, 1998.

7. Bisbis S, Bailbé D, Tormo MA, Picarel-Blanchot F, Derouet M, Simon J, Portha B. Insulin resistance in the GK rat: decreased number but normal kinase activity of insulin receptor in the liver. Am J Physiol Endocrinol Metab 265: E807-E813, 1993.

8. DeFronzo R, Bonadonna R, Ferrannini E. Pathogenesis of NIDDM. International Texbook of Diabetes Mellitus. New York: Wiley and Sons, 1997, p. 635-712.

9. Dominici FP, Hauck S, Argentino DP, Bartke A, Turyn D. Increased insulin sensitivity and upregulation of insulin receptor, insulin receptor substrate IRS-1 and IRS-2 in liver of Ames dwarf mice. J Endocrinol 173: 81-94, 2002.

10. Escriva F, Rodriguez C, Cacho J, Alvarez C, Portha B, Pascual-Leone AM. Glucose utilization and insulin action in adult rats submitted to prolonged food restriction. Am J Physiol Endocrinol Metab 263: E1-E7, 1992.

11. Fahrenkrog S, Harder T, Stolaczyk E, Melchior K, Franke K, Dudenhausen JW, Plagemann A. Cross-fostering to diabetic rat dams affects early development of mediobasal hypothalamic nuclei regulating food intake, body weight and metabolism. J Nutr 134: 648-654, 2004.

12. Fernandez-Castaner M, Biarnes J, Camps I, Ripolles J, Gomez N, Soler J. $\beta$-Cell dysfunction in first-degree relatives of patients with non-insulin-dependent diabetes mellitus. Diabet Med 13: 434-440, 1996.

13. Fernandez-Twinn DS, Ozanne SE, Ekizoglou S, Doherty C, James L, Gusterson B, Hales CN. The maternal endocrine environment in the low-protein model of intra-uterine growth restriction. $\mathrm{Br} J$ Nutr 90: 815-822, 2003.

14. Ferrannini E, Gastaldelli A, Miyazaki Y, Matsuda M, Mari A, DeFronzo RA. $\beta$-Cell function in subjects spanning the range from normal glucose tolerance to overt diabetes: a new analysis. J Clin Endocrinol Metab 90: 493-500, 2005.

15. Gavete ML, Martin MA, Akvarez C, Escriva F. Maternal food restriction enhaces insulin-induced GLUT-4 translocation and insulin signaling pathway in skeletal muscle from suckling rats. Endocrinology 146: $3368-$ 3378, 2005.

16. Gerich JE. The genetic basis of type 2 diabetes mellitus: impaired insulin secretion versus impaired insulin sensitivity. Endocr Rev 19: 491-503, 1998.

17. Gill Randall R, Adams D, Ollerton RL, Lewis M, Alcolado JC. Type 2 diabetes mellitus - genes or intrauterine environment? An embryo transfer paradigm in rats. Diabetologia 47: 1354-1359, 2004.

18. Goto Y, Kakizaki M, Masaki N. Production of spontaneous diabetes by repetition of selective breeding. Tohoku J Exp Med 119: 85-90, 1976.

19. Goursot R, Portha B, Levacher C, Picon L. Effect of early and chronic hypoinsulinism on adipose tissue cellularity in the rat. Diabetologia 21: 418-421, 1981.

20. Herrera E, Amusquivar E. Lipid metabolism in the fetus and the newborn. Diabetes Metab Res Rev 16: 202-210, 2000.

21. Holness MJ. Impact of early growth retardation on glucoregulatory control and insulin action in mature rats. Am J Physiol Endocrinol Metab 270: E946-E954, 1996.

22. Jimenez-Chillaron JC, Hernandez-Valencia M, Reamer C, Fisher S, Joszi A, Hirshman M, Oge A, Walron S, Przybyla R, Boozer C, Goodyear LJ, Patti ME. $\beta$ Cell secretory dysfunction in the pathogenesis of low birth weight-associated diabetes. A murine model. Diabetes 54: 702-711, 2005.

23. Katakura M, Komatsu M, Sato Y, Hashizume K, Aizawa T. Primacy of $\beta$-cell dysfunction in the development of hyperglycemia: a study in the Japanese general population. Metabolism 53: 949-953, 2004.

24. Kergoat M, Guerre-Millo M, Lavau M, Portha B. Increased insulin action in rats with mild insulin deficiency induced by neonatal streptozotocin. Am J Physiol Endocrinol Metab 260: E561-E567, 1991.

25. Knittle JL, Hirsch J. Effect of early nutrition on the development of rat epididymal fat pads: cellularity and metabolism. J Clin Invest 47: 20912098, 1968.

26. Lau C, Sullivan MK, Hazelwood RL. Effects of diabetes mellitus on lactation in the rat. Proc Soc Exp Biol Med 204: 81-89, 1993.

27. Law CM, Barker DJP, Osmond C, Fall CHD, Simmonds SJ. Early growth and abdominal fatness in adult life. J Epidemiol Community Health 46: 184-186, 1992.

28. Lemonnier D, Suquet JP, Aubert R, Rosselin G. Long term effect of mouse neonate food intake on adult body composition, insulin and glucose serum levels. Horm Metab Res 5: 223-224, 1973.

29. Liu JL, Karen T, Coschigano KT, Robertson K, Lipsett M, Guo Y, Kopchick JJ, Kumar U, Liu YL. Disruption of growth hormone receptor gene causes diminished pancreatic islet size and increased insulin sensitivity in mice. Am J Physiol Endocrinol Metab 287: E405-E413, 2004.

30. Matthaei SM, Stumvoll M, Kellerer M, Haring HU. Pathophysiology and pharmacological treatment of insulin resistance. Endocr Rev 21: 585-618, 2000.

31. Movassat J, Saulnier C, Portha B. $\beta$-Cell mass depletion precedes the onset of hyperglycemia in the GK rat: a genetic model of non-insulindependent diabetes mellitus. Diabetes Metab 21: 365-370, 1995.

32. Movassat J, Saulnier C, Serradas P, Portha B. Impaired development of pancreatic $\beta$-cell mass is a primary event during the progression to diabetes in the GK rat. Diabetologia 40: 916-925, 1997.

33. Murphy HC, Regan G, Bogdarina IG, Clark AJ, Iles RA, Cohen RD, Hitman GA, Berry CL, Coade Z, Petry CJ, Burns SP. Fetal programming of perivenous uptake reveals a regulatory mechanism governing hepatic glucose output during refeeding. Diabetes 25: 1326-1332, 2003.

34. Olefsky J. Diabetes mellitus (type II): etiology and pathogenesis. In: Endocrinology, edited by DeGroot L, Besser M,Burger H, Jameson J, Loriaux D, Marshall J, O’Dell W, Potts J, Rubenstein A. Philadelphia, PA: W. B. Saunders, 1995, p. 1436-1463.

35. stenson CG. The Goto-Kakizaki rat. In: Animal Models of Diabetes: A Primer, edited by Sima AAF and Shafrir E. Amsterdam: Harwood Academic, 2000, p. 197-211. 
36. Pénicaud L, Ferré P. Development of insulin resistance during the course of obesity: lessons from animal models. J Obesity Weight Regul 7: 91-109, 1998.

37. Picarel-Blanchot F, Berthelier C, Bailbé D, Portha B. Impaired insulin secretion and excessive hepatic glucose production are both early events in the diabetic GK rat. Am J Physiol Endocrinol Metab 271: E755-E762, 1996.

38. Plagemann A, Harder T, Franke K, Kohlhoff R. Long-term impact of neonatal breast feeding on body weight and glucose tolerance in children of diabetic mothers. Diabetes Care 24: 16-22, 2002.

39. Portha B, Serradas P, Bailbé D, Suzuki K, Goto Y, Giroix MH. $\beta$-Cell insensitivity to glucose in the GK rat, a spontaneous non-obese model for type II diabetes. Diabetes 41: 486-491, 1991.

40. Portha B, Giroix MH, Serradas P, Gnagnereau MN, Movassat J, Rajas F, Bailbe D, Plachot C, Mithieux G, Marie JC. $\beta$-Cell function and viability in the spontaneously diabetic GK rat. Information from the GK/Par colony. Diabetes 50: 89-93, 2001.

41. Reifsnyder PC, Churchill G, Leiter EH. Maternal environment and genotype interact to establish diabesity in mice. Genome Res 10: $1568-$ 1578, 2000.

42. Rogers I. The influence of birth weight and intrauterine environment on adiposity and fat distribution in later life. Int J Obes 27: 755-777, 2003.
43. Serradas P, Gangnerau MN, Giroix MH, Saulnier C, Portha B. Impaired pancreatic $\beta$-cell function in the fetal GK rat. Impact of diabetic inheritance J Clin Invest 101: 899-904, 1998.

44. Sjöström L, Björntorp P, Vrana J. Microscopic fat cell size measurements on frozen-cut adipose tissue in comparison with automatic determinations of osmium-fixed fat cells. J Lipid Res 12: 521-530, 1971.

45. Soto N, Bazaes RA, Peña V, Salazar T, Avila A, Íniguez G, Ong KK, Dunger DB, Mericq V. Insulin sensitivity and secretion are related to catch-up growth in small-for-gestational-age infants at age 1 year: results from a prospective cohort. J Clin Endocrinol Metab 88: 3645-3650, 2003.

46. Valdez R, Athens MA, Thompson GH, Bradshaw BS, Stern MP. Birth weight and adult health outcomes in a biethnic population in the USA. Diabetologia 37: 624-631, 1994.

47. Van Haeften T, Dubbeldam S, Zonderland M, Erkelens D. Insulin secretion in normal glucose-tolerant relatives of type 2 diabetic subjects. Assessments using hyperglycemic glucose clamps and oral glucose tolerance tests. Diabetes Care 21: 278-282, 1998.

48. Weir GC, Bonner-Weir S. Insulin secretion in type 2 diabetes. In: Diabetes Mellitus. A Fundamental and Clinical Text (2nd ed.). Philadelphia, PA: Lipincott Williams \& Wilkins, 2000, p. 595-603.

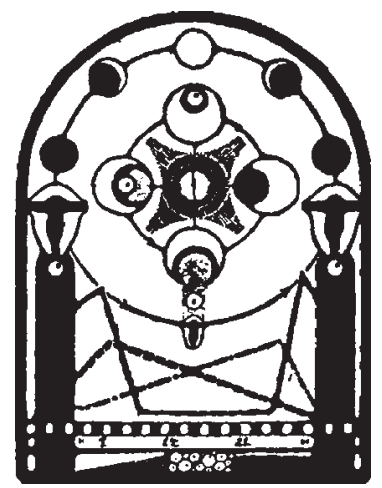

